\title{
TAPE AUTOMATED BONDING FOR HIGH DENSITY PACKAGING
}

\author{
KAREL KURZWEIL \\ CII-Honeywell Bull, Rue Jean Jaurès, 78340 Les Clayes-sous-Bois, France
}

\begin{abstract}
High density packaging of semiconductor devices is necessary for high performance in compact electronic systems. But the assembly technology must also remain cost attractive.

Through the development efforts conducted during the past years in the world, the Tape Automated Bonding $\mathrm{TAB}$ - has become the assembly technology allowing a very high density packaging. In combination with substrate technology it has grown into a complete, cost effective, micropackaging concept.

The paper describes the main technical characteristics of this packaging concept. Specific equipments for TAB were designed and built by CII-Honeywell Bull for installation in the factory. These equipments are not only those, directly related to the TAB technology processing steps but include also other equipments like high precision thick film printer.

The main features of the new micropackaging facility are also presented. Some examples of high density packages built with tape automated bonding are described and some of the main quality and reliability aspects are discussed.
\end{abstract}

\section{INTRODUCTION}

\subsection{Density in Packaging}

The hardware changes and improvements in computer construction stay in the shadow of impressive well publicized computer applications. All these rapidly growing applications and new computer generations are however closely related to new hardware concepts. Tape Automated Bonding, TAB, is one of such new hardware concepts with a strong impact not only on packaging of computers but on component interconnection in any electronic assembly.

Preliminary investigations in the early 70 's have shown that the TAB concept has a strong potential not only for computer performance improvement but also for a significant hardware cost reduction. Higher component packaging density is desired by each manufacturer, i.e. increased performance at reduced cost. Higher component density allows shorter interconnection which improves performance and which also results in a smaller overall volume for the general assembly, which in turn reduces costs.

The TAB technology has been thoroughly evaluated over many years and many prototype assemblies have been realized during that time ${ }^{1}$. All prototype evalutations have demonstrated the capacity of TAB as a technology suitable for high density packaging.

\subsection{Micropackaging Concept with TAB}

The name TAB - Tape Automated Bonding essentially refers to a method of component handling as already previously described. ${ }^{1}$ The name is however used sometimes, not quite correctly, to address a broader subject, including hybrid substrate assembly. Figure 1a shows a completely assembled substrate with use of TAB technology. The substrate itself is made using thick film technology. ${ }^{2}$

Three conductive layers on a 2 in. $\times 2$ in. alumina substrate are used to make the substrate shown. The integrated circuits are assembled by means of the $\mathrm{TAB}$ process. Finally all other components, like capacitors, lead frames and heat sink are assembled on the substrate by processes similar to those used in conventional hybrid microelectronic assembly. In spite of their more conventional character, the assembly processes and thick film process were, together with the TAB process, the subject of intense development work to elaborate a coherent micropackaging concept.

The micropackaging concept has been under elaboration by the advanced development group in Saint-Ouen since the early 70's. This development did not only concern process investigations but the impact of the micropackaging concept on the overall computer performance has been also studied.

These studies included the construction of several prototype units built using micropackaging technology. 


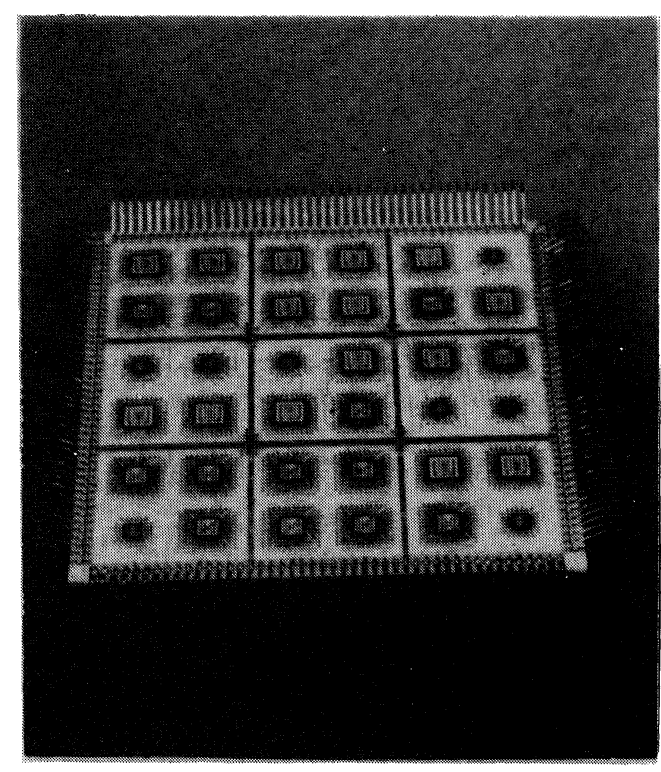

FIGURE 1a Substrate populated with TAB bonded chips; 2 in. $\times 2$ in. alumina substrate, 3 conductor layers, heat sink, external lead frames.

During the studies performance measurements and a detailed record of the cost of the micropackaging technology were kept and even in the early part of the work special attention has been given to the quality aspects. Qualification of the components and reliability performance of the built prototypes have been under continuing control.

Concluding the development activity, it was decided in 1977 to implement the TAB technology in the factory in Angers as a basic assembly technology for a new generation of computers. (Figure 1b).

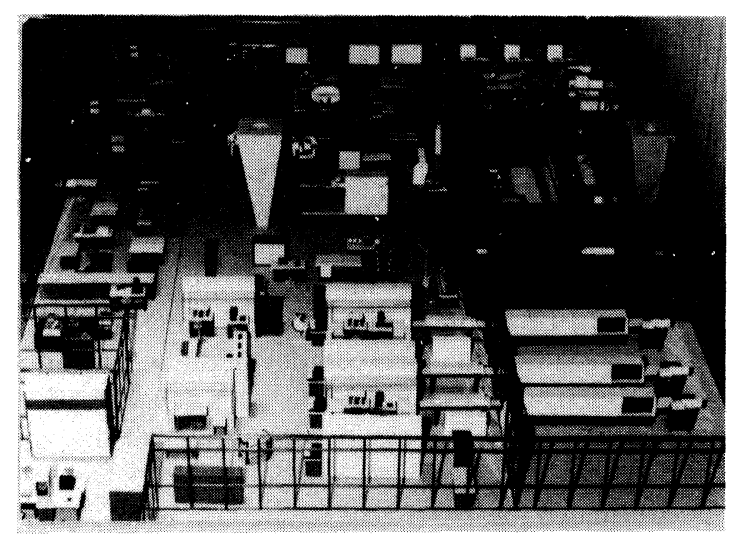

FIGURE 1b Partial view of manufacturing site. Reduced scale model.

\section{TAB IN VOLUME PRODUCTION}

The original development work of the micropackaging concept was always carried on with final implementation in the factory in mind. Therefore a high degree of automation has been included even in the equipment developed for the laboratory use.

Some of the equipment could thus have been almost directly duplicated to fulfil production needs. Some other machines have been specially developed and installed directly in the factory. Some of the most significant new machines and equipments are discussed after some general information about the facility lay-out.

\subsection{Micropackaging Facility Lay-out}

Figure 2 shows the approximate arrangement of the area established for TAB, thick film and assembly processes. The total area of $1300 \mathrm{~m}^{2}$ has been conceived as an open space, with a general cleanliness class 10,000 and it is temperature controlled. The open space concept is at present frequently used in modern semiconductor facilities. In addition to a more fluent product circulation it offers more flexibility when for any reason the area lay-out has to be remodelled.

Separation by transparent walls was provided only where needed by the process itself. These are specifically areas where chemicals are handled and thus special exhaust is required and areas where photosensitive work is performed. At some work stations clean benches of class 100 have been installed together with tighter temperature control.

The facility was installed on the first floor of an existing factory building. To avoid any perturbation of the precise micropackaging work the entire floor

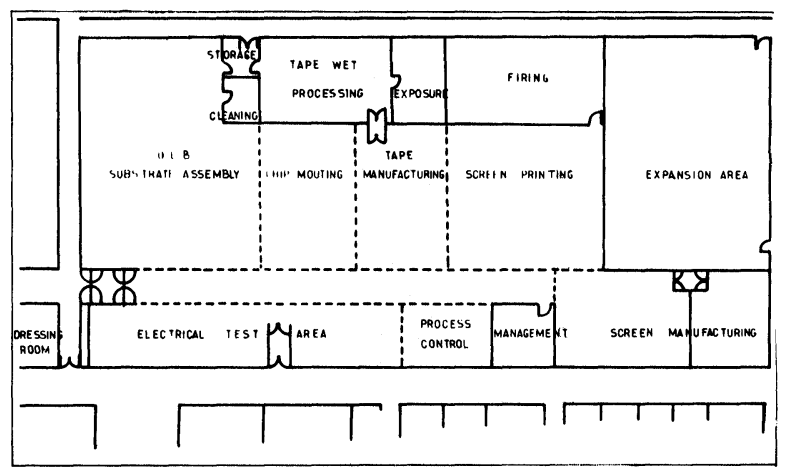

FIGURE 2 Lay-ouı of the micropackaging manufacturing facility. Total area is $1300 \mathrm{~m}^{2}$. Solid lines represent glass walls, dashed lines represent theoretical boundaries between communicating areas. 
surface was covered with a vibration absorbing concrete plate. Thus all vibrations generated on the floor or in the ground floor are eliminated from the area. The access from the ground floor is in part used to service the overall micropackaging area with the distribution of all fluids.

As a general rule all specific test equipments have been implemented next to each specific processing area. Products being manufactured can be easily tested and are transmitted to the following area only if they are satisfactory.

\subsection{Tape Fabrication and ILB Equipment}

Material cost studies led to the selection of mylar as the base material for making the tape. This material is processed in a set of automatic equipment to provide the finished $35 \mathrm{~mm}$ wide tape for chip inner lead bonding. Perhaps the most significant new addition to already described equipment is a fully automated line for all wet processes.

A further automation of the bonding process itself was achieved by developing with JADE Corporation an Inner Lead Bonder (ILB) (Figure 3) on which the lead forming operation is integrated together with bonding on a single machine. This integration eliminates the forming as a special separate step.

A relatively simple forming mechanism is mounted next to the bonding head. All positions are serially

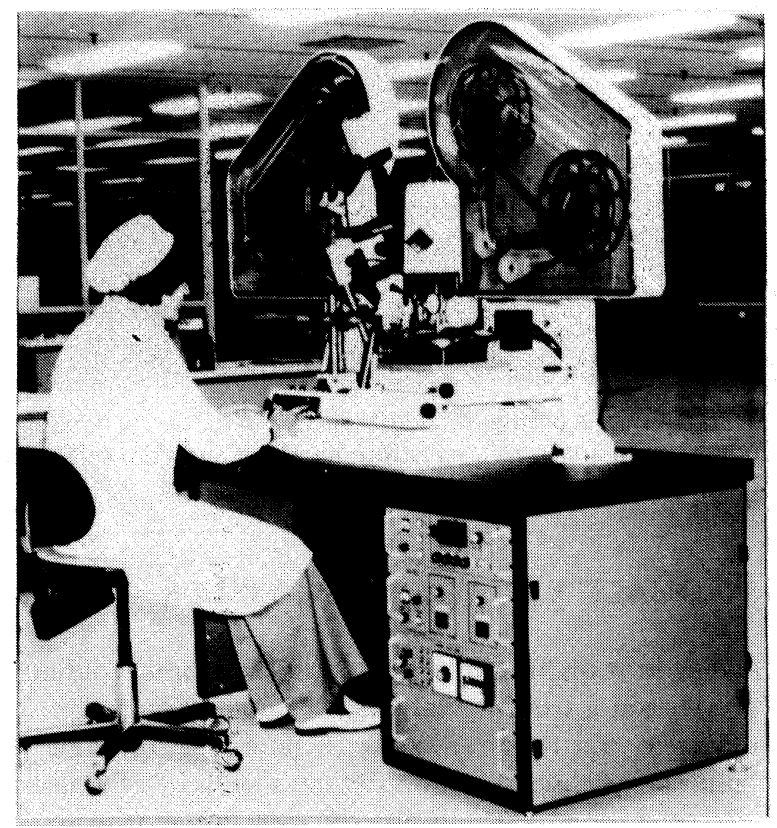

FIGURE 3 JADE Inner Lead Bonder. The lead forming station is integrated on the bonder to CII-HB specification. formed directly after bonding. Forming on the tape has several advantages over the optional lead forming on separated chips. Of main interest is the simplicity resulting in the concept of Outer Lead Bonders (OLB) and the increased accuracy of lead positions as their extremity is maintained during forming.

\subsection{Thick Film Equipment}

A new printer is the key new equipment in this area. The density of multilayer substrates requires a high degree of precision and accuracy. None of the commercially available printers was found to meet our requirements. An in-house designed and built printer (Figure 4) became the solution of the alignment problem.

The motions of the MILMATIC printer are all electrically driven, substrate loading and unloading are

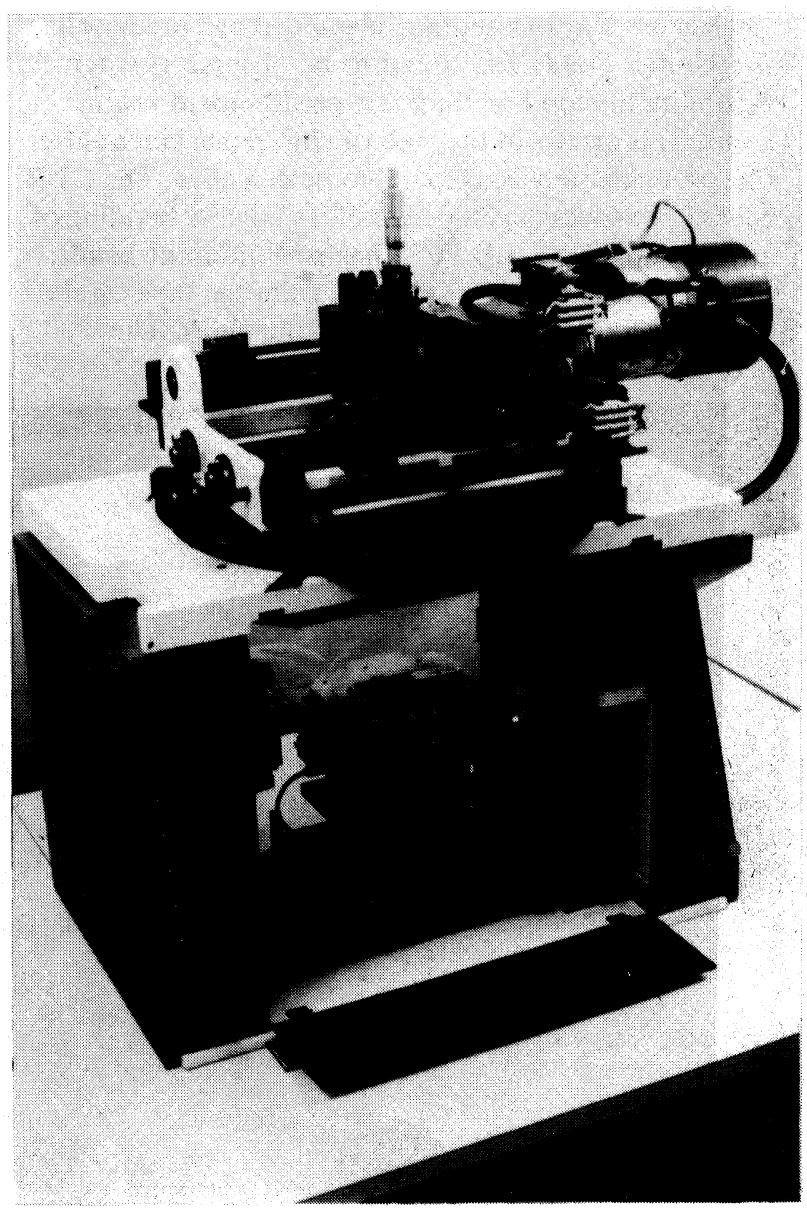

FIGURE 4 MILMATIC high precision thick film printer. The machine designed and built by CII-HB is specially tailored for dense multi-layer printing. 
automated. Pre-aligned screens are automatically registered when loaded on the printer. One of the most characteristic features is a rotating patented printing head. The sense of the print can be selected between two perpendicular directions and changed by a simple rotation of the squeegee carrying printing head, leaving screen and substrate positions unchanged and thus keeping original registration. This allows printing in the predominant sense of the conductor lines which is essential for fine line printing.

\section{$2.4 O L B$ and Assembly Equipment}

In addition to the original automatic machine which works simultaneously with up to ten different chip types, each on a different reel of tape, two new machines were developed and installed in the factory. They both use chips presented individually in slide type carriers (Figure 5).

This new way of handling developed by Honeywell in the United States was found to be of interest when flexibility in chip handling is a predominant requirement. This occurs in the case of chip replacement after one particular device is found to be defective. The OLB Model 7054 was developed to allow an easy bonding of a new chip. The OLB 7054 has two different heads. One head transfers chips directly from the tape on the substrate, the second head bonds the chips. The

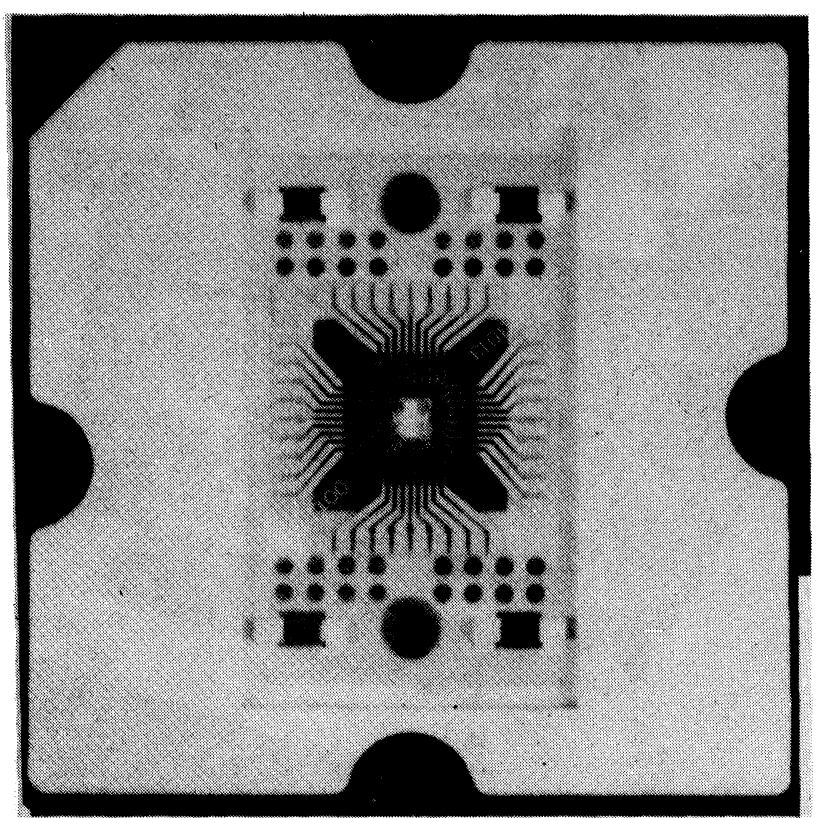

FIGURE 5 TAB bonded chip in plastic slide carrier. This approach patented by Honeywell U.S. allows possibility of individual handling. (Dimensions $50 \times 50 \mathrm{~mm}$.) machine is relatively simple because it does not perform lead forming which is done on tape directly on the ILB machine as already mentioned.

OLB 7054 does not necessarily require chip supply in slide frames. A version of the machine using individual tape positions is also used.

The same machine can also be used to populate short runs of substrates in a semi-automatic mode.

Increased flexibility in chip handling is required also when a large number of chip types is to be assembled on substrates which are presented for bonding in short runs of a large variety of types. A machine which automatically selects appropriate chips from slide magazines, places and bonds them on substrates using the same principle as the OLB 7054, has been developed and built by the Swiss Company FARCO to our specifications (Figure 6).

Other automatic machines were developed to bond capacitors on substrates and to attach lead frames on all four substrate edges and the heat sink on the back of the substrate.

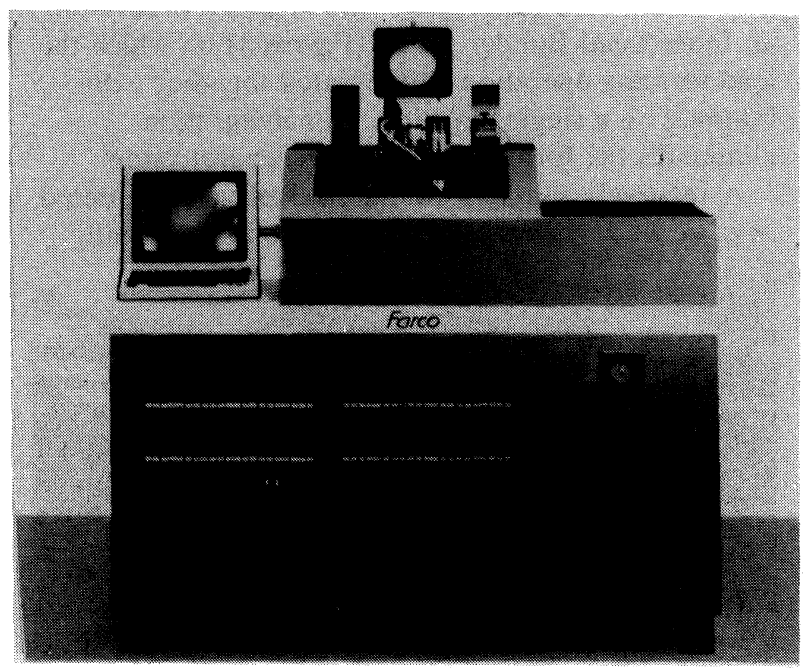

FIGURE 6 Automatic OLB built by FARCO. Automatic bonder with automated substrate handling and chip selection from slide magazines.

\section{QUALITY, RELIABILITY, YIELDS}

As for introduction of a new technology into volume production a careful evaluation of quality and reliability was required. A systematic logging of all failures and defects with a detailed analysis of causes was established early during the development in addition to specially tailored qualification and reliability actions. 
In many cases new testing equipments were required for the program, like test equipments for nonpopulated substrates or for chips on tapes. Some new testers with special handling and probing fixtures were developed in-house, others were developed in cooperation with specialized companies.

The multichip substrate design was conducted to minimize touch-up and repair in manufacturing to keep the product quality at a high level with a minimum cost.

The repair techniques are however required to replace a defective component or to allow a correction of design errors. These techniques were also developed and their impact on product reliability has been qualified.

\subsection{Quality and Reliability Aspects}

The new way of component handling on tapes, the presence of new materials have required a number of specific studies and evaluations, some were carried in cooperation with Honeywell Corporate Material and Science Center, for example the study of inner lead bonding metallurgy ${ }^{3}$ or the comparison of efficiency of different cleaning methods.

Other tests have shown excellent behaviour of TAB bonded parts under severe temperature shocks and in extended exposure to extreme temperatures.

These actions together with a number of quality control steps introduced in the manufacturing process guarantee a high quality level of the manufactured multichip micropackages. Data obtained from experimentation and early data obtained from field reports indicate, that product reliability is well above the reliability achieved on products made with conventional dual in line packages.

Qualification and reliability tests and field data have also confirmed that the TAB process is free of any kind of new specific failure mechanism not seen in conventional packaging.

\subsection{Yields}

The high degree of automation achieved in tape automated bonding results not only in a high quality and reliability but it is also the basis of high yields achieved in production.

Ambitious goals for yields were set for the TAB technology in manufacturing. They are progressively being reached in all different areas.

As an example, only much less than one percent of chips are to be replaced on populated substrates after electrical testing. That means that the vast majority of substrates carrying each an average of 30 complex integrated circuits are completely good as they leave the manufacturing area for the first electrical test.

\section{CONCLUDING REMARKS}

The Tape Automated Bonding and the total micropackaging concept conceived around this original assembly technology are now well established in our manufacturing plant in Angers. Facility lay-out elaboration and installation of equipment were not the only tasks to manage. The introduction of this new technology in the production factory has made retraining of production personnel necessary.

Retraining of personnel responsible for micropackaging and manufacturing was also necessary.

A high degree of automation which is an inherent part of TAB and of the micropackaging technology in general is the best guarantee of a high and constant level of the product quality. Present data shows that the ambitious goal of significant improvement in reliability of finished products over results achieved with conventional packaging will be easily obtained.

The micropackaging technology with TAB is today's significant new step in the history of computer hardware development. The TAB micropackaging applications are not limited to computers only. The present tremendous development of electronics in telecommunications, automobile industry, other consumer and all other electronic applications needs denser and cheaper packaging solutions. Tape Automated Bonding is one of the possible answers. Given the many licence agreements already granted and many different negotiations we have under way and considering the solid implementation of TAB in Japan and in the United States. Tape Automated Bonding is a technology which has made its place in the industry.

\section{REFERENCES}

1. G. Dehaine and K. Kurzweil, Tape Automated Bonding Moving into Production, Solid State Technology (October 1975).

2. J. Loughran and K. Kurzweil, Economie Considerations in Multilayer Thick Film Hybrids, IEE Transactions, Vol. PHP 10 (June 1974).

3. T. S. Lieu, Aspects of gold-tin bump-lead interconnection metallurgy, Proceedings International Microelectronic Conference (ISHM, US) 1977. 

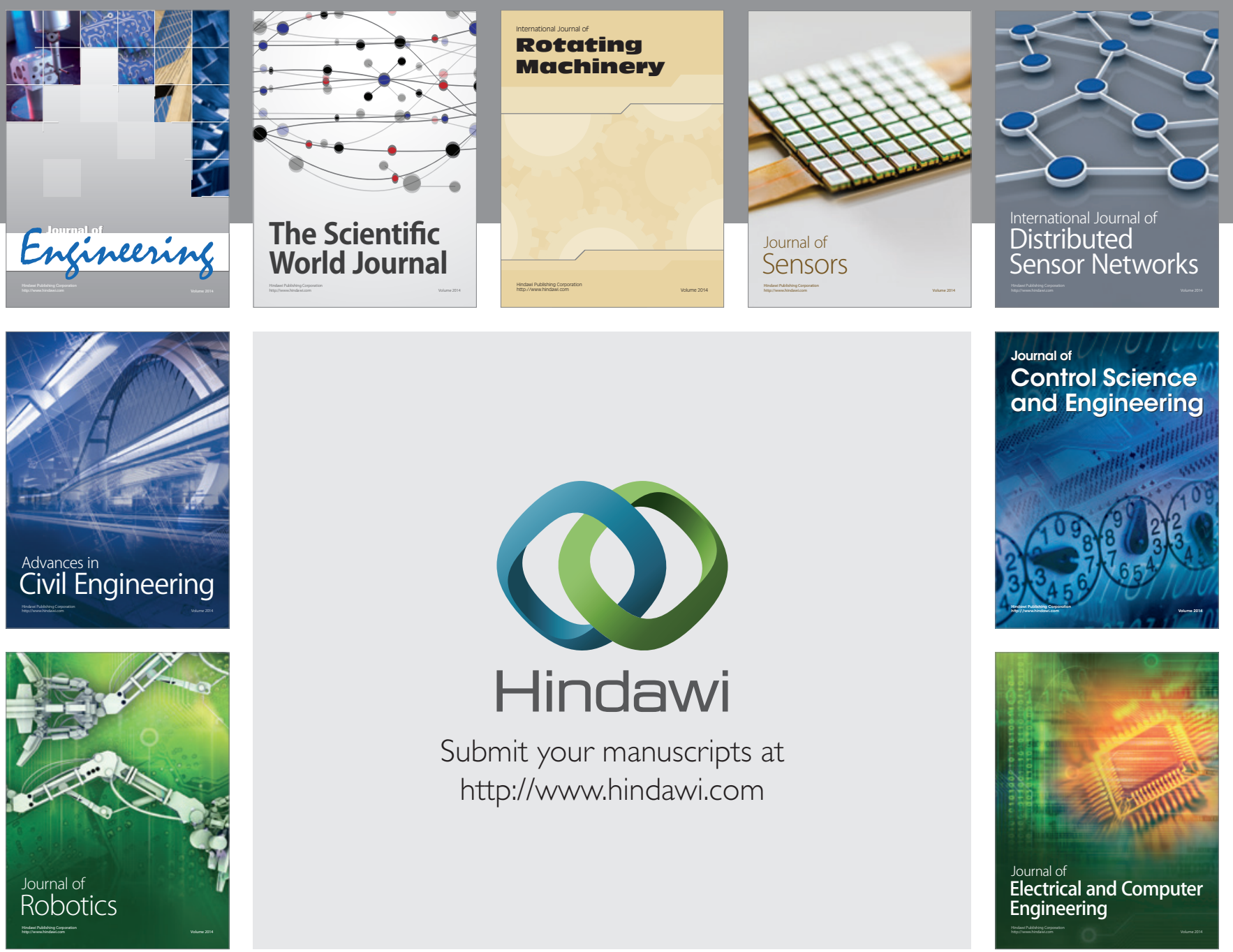

Submit your manuscripts at

http://www.hindawi.com
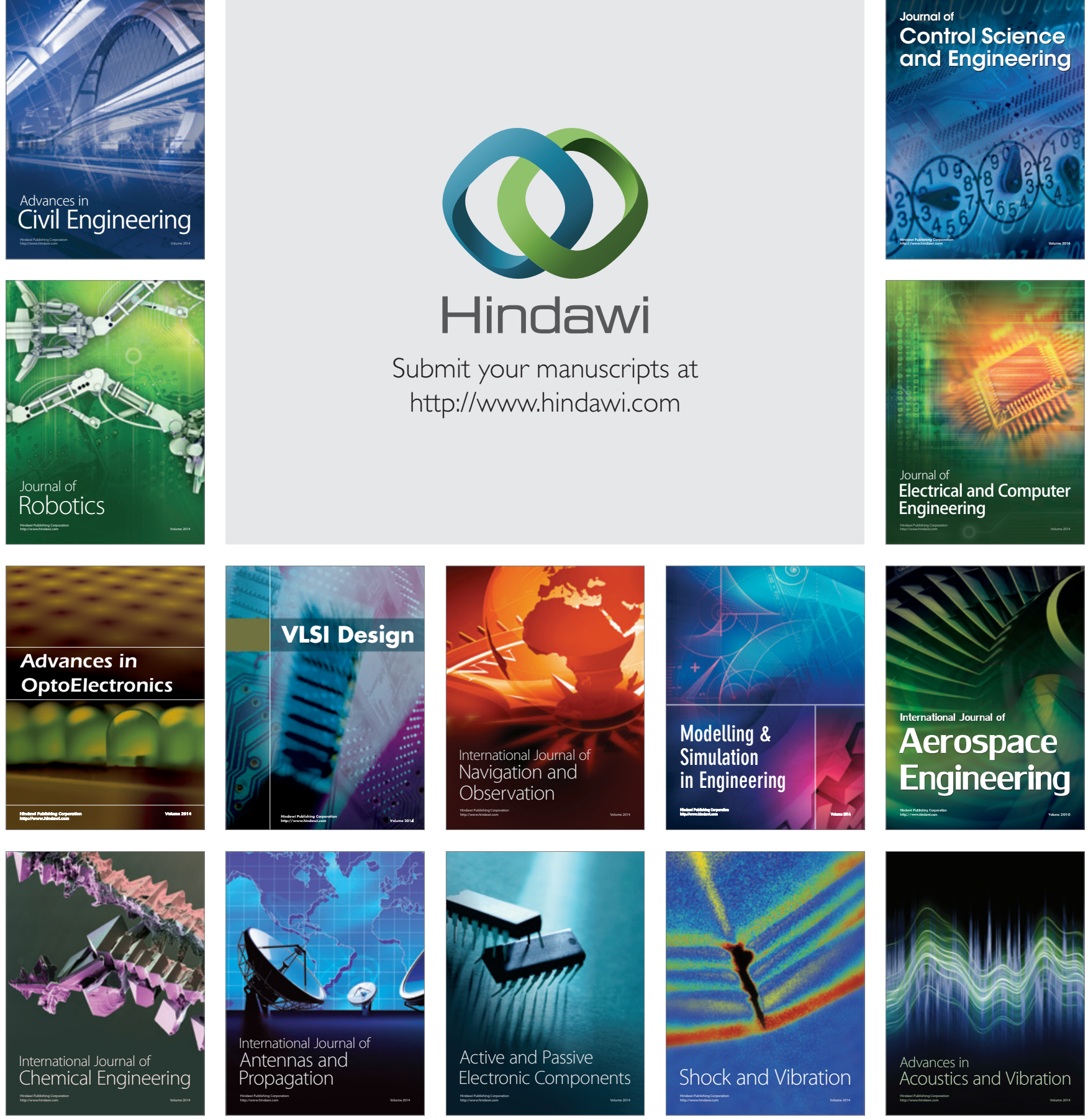